International Journal of Agriculture, Environment and Bioresearch

Vol. 06, No. 03; 2021

ISSN: $2456-8643$

\title{
DEVELOPMENT AND VALIDATION OF A MOBILE APP FOR THE DIAGNOSIS OF HEAT STRESS IN LIVESTOCK ANIMALS
}

\author{
Sergio Luís de Castro Junior*, Glauber da Rocha Balthazar and Iran Jose Oliveira da Silva \\ Livestock Environment Research Group, Luiz de Queiroz College of Agriculture - University of São Paulo \\ (ESALQ/USP), Av. Pádua Dias, 11, 13418-900, Piracicaba/SP, Brazil
}

https://doi.org/10.35410/IJAEB.2021.5639

\begin{abstract}
This paper aims to present the development and validation of a mobile application - titled Animalcomfort - designed for the Android platform to monitor livestock animals' thermal comfort situation. The processing was based on calculating the specific enthalpy of the air, resulting in the animals' comfort situation and the diagnosis based on changes in the environment. The app was developed considering four main functions, using different input data sources: open environment (satellite), closed environment (Arduino® sensor), manual calculation, and forecast for the next seven days (satellite). The software was initially designed from the users' perspective, using UML notation as documentation. The app development was conducted following the agile Scrum methodology and programmed in Java. The resulting product was evaluated by potential users (producers, scientists, and students), revealing desirable design, terminology, learning, and usability characteristics. In conclusion, Animalcomfort represented a high potential tool for quick, easy, and affordable management in identifying heat stress in livestock animals, directly assisting in the decision-making of best alternatives in productive environmental management.
\end{abstract}

Keywords: Android; Specific Air Enthalpy; Usability; Thermal Comfort; Livestock Environment.

\section{INTRODUCTION}

Based on the development of software and hardware, new technologies have been incorporated into the livestock production systems, which have been exponentially modernized over the past few years. Within the conceptualization of "smart farms" and "agriculture 4.0", such tools have as their primary function to assist in decision making on farms, potentiating animal performance, reducing economic risks, and proposing new systems that increase desirable conditions, as an example, animal welfare (Ryu et al., 2015; Wolfert et al., 2017).

Heat stress becomes a critical issue when livestock animals are housed in regions where tropical and subtropical climates predominate. Heat stress occurs when homeothermic animals are exposed to environmental conditions that offer challenges to their thermoregulation (Slimen et al., 2016; Gao et al., 2017; Rashamol et al., 2018), which has adverse effects on their overall performance. 
Although the harmful effects of heat stress on the multiple stages of livestock breeding and its impact on the quality of final products are widely known (Cowley et al., 2015; Slimen et al., 2016; Quintão et al., 2017; Rashamol et al., 2018; Nordlund et al., 2019; Nyoni et al., 2019), the management of macro and microclimate data is still scarce from a practical standpoint and done irregularly in most of the farms. The first issue is that, in many cases, data from the building environment are not recorded, sometimes being limited only to the investigation of air temperature (Brown-Brandl et al., 2013). Consequently, essential variables such as air relative humidity, atmospheric pressure, and other environmental characteristics relevant to determining heat stress are disregarded (Aziz et al., 2016).

As a second and common issue, when recorded, the data collected do not produce valid information to develop strategies that reduce the effects of heat stress on commercial buildings. Krishnan et al. (2017) reported that the mismanagement of the climate data leads to incomplete or inconclusive information or even erroneous decision making.

Currently, data management is migrating to mobile devices, such as smartphones and tablets, as applications (apps) that allow more direct and frequent access to information and enable adaptations for individual use (Liu et al., 2014). Launched by Google in 2008, Android is the most extensive operating system globally in this segment, with the advantages of its open-source license and the development of high-tech and relatively low-cost apps.

In the recent literature, studies aimed to develop mobile apps to assess heat stress in farm animals: Dalmedico et al. (2016) used manual data entry - provided by the user - to calculate the BGTHI (Black Globe Temperature and Humidity Index) for broiler birds, while Oliveira Junior et al. (2018) used data collected from a sensor device to determine the thermal comfort of different animals based on the THI (Temperature and Humidity Index) and BGTHI. However, comfort indexes such as THI and BGTHI have some limitations (Martello et al., 2004): they were developed for North American and European regions and are also based on a regression model considering an outdated animal performance.

In contrast, the psychometric evaluation of air appears as a methodological proposal only based on the environment. It involves a set of variables that characterize ambient air in a combined manner, such as the specific air enthalpy, described as the amount of energy existent in a unit of a dry air mass. According to Chu and Jong (2008), Rodrigues et al. (2011), Heidari et al. (2016), Heidari et al. (2018), and Sarnighausen (2019), specific air enthalpy has been used as an index of thermal comfort, incorporating in its calculation the interaction of air temperature, relative humidity, and location atmospheric pressure.

The objective of this work was to design and develop, in addition to validating from the user's perspectives, a mobile app - entitled Animalcomfort - developed for the Android operating system permitting the diagnosis of the heat stress situation of farm animals.

\section{MATERIAL AND METHOD}




\subsection{Processing principles}

The logical processing to diagnose the animals' heat stress was based on psychrometric principles and the specific air enthalpy. The inputs (boxes in blue), processing (box in yellow), and outputs (boxes in green) are represented in Figure 1.

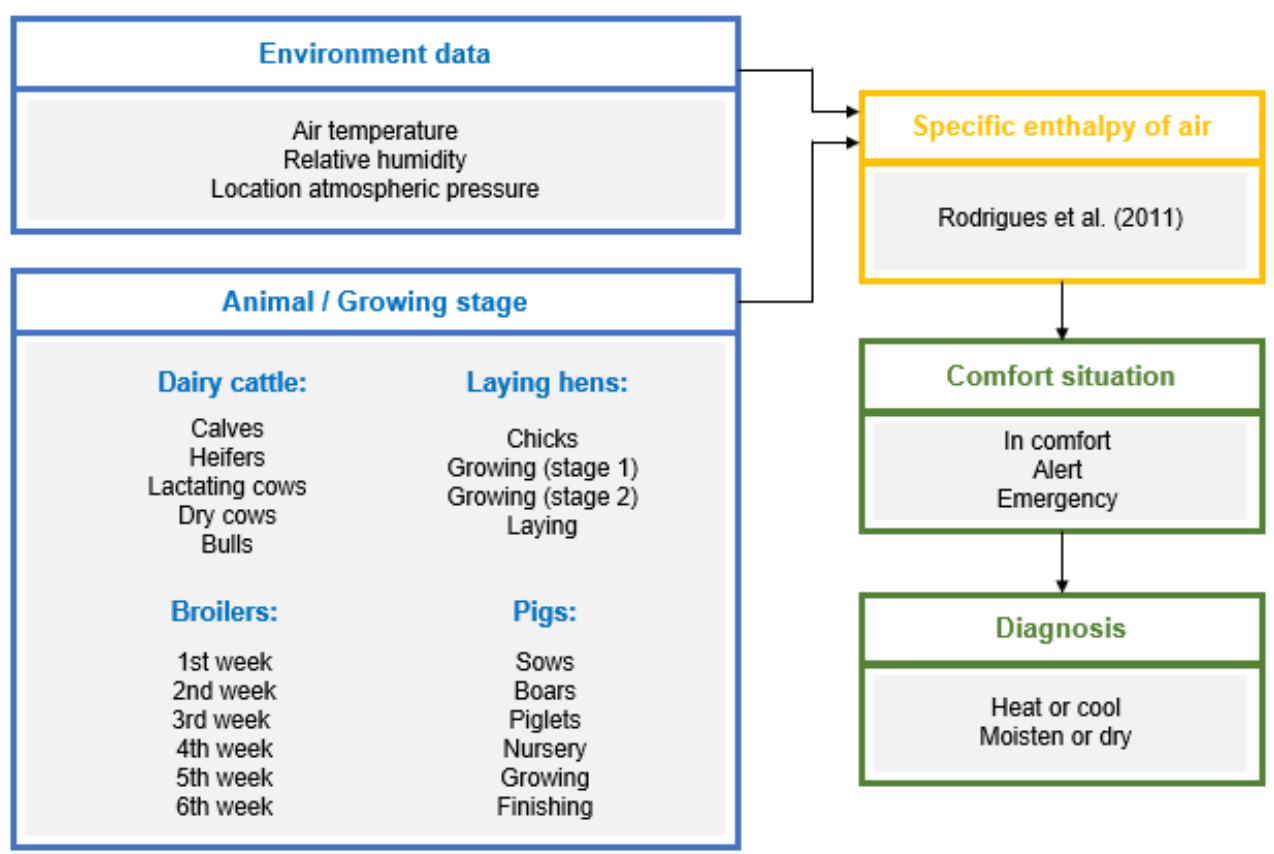

Figure 1. The processing system of the app: input data (boxes in blue), processing (box in yellow), and output data (boxes in green).

The first set of input data corresponds to the selection of farm animals. This work is focused on the characterization of the thermal comfort of dairy cattle, pigs, laying hens, and broilers. However, as each animal responds differently to environmental changes according to its growth (Ribeiro et al., 2018), it was necessary to subdivide the animals of interest in their respective growing stages ( 6 categories for broilers and pigs, 5 categories for dairy cattle, and 4 categories for hens).

Psychrometric properties of the air were incorporated as input data, considering in this work the dry bulb temperature $(\mathrm{Ta})$, the relative humidity $(\mathrm{RH})$, and the location atmospheric pressure $(\mathrm{Pa})$. For the internal processing of the app, it was used the equation proposed by Rodrigues et al. (2011) (Eq. 1), which calculates the specific air enthalpy (h).

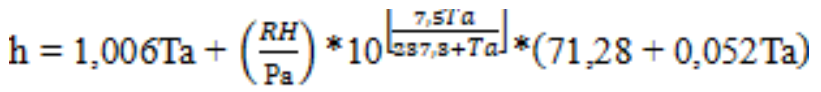


Vol. 06, No. 03; 2021

ISSN: $2456-8643$

As output information, the situation of the heat stress condition and the diagnosis of problems related to the environment were determined. In order to characterize heat stress, the referential parameters of specific air enthalpy were applied for each animal/growing stage, according to the participation of the experts in the area and using a set of 189 reference records. The comfort situation was classified into three groups: animals in thermal comfort ( $\mathrm{h}$ within the thermoneutral zone); animals in a state of alert (values of $h$ between ideal $h$ and critical $h$ ); and animals in an emergency (h above critical h). Alert and emergency states represent levels of heat stress in the animals.

As a second output, the diagnosis uses the results of $h$, added to the parameters of Ta and $\mathrm{RH}$, to identify possible psychrometric issues in the environment where these animals are housed. It was considered psychrometric processes of heating, cooling, drying, and humidification of the air, as presented by Britto (2010) and Kresta and Ayranci (2018). Diagnoses were categorized from D1 to D7, being: D1 = ideal environment, with h within the comfort zone; D2 = hot and humid environment, with $\mathrm{Ta}$ and $\mathrm{RH}$ above the recommended; D3 = warm environment, with high Ta; D4 = humid environment, with high RH; D5 = cold and dry environment, with low Ta and RH; D6 = cold environment, with low Ta; D7 = dry environment, with low RH.

\subsection{App features}

For the practical application of the logical processing, previously exposed, the design of a software - mobile app - for the Android operating system was proposed based on multiple possibilities of the data record.

As a starting point, it was suggested the development of a use-case diagram, which is a behavioral model included in the set of UML (Unified Modeling Language) representations. The UML modeling language assists in investigating system requirements, thus being recommended as a platform for documentary application design (Kang and Park, 2016). The diagram was developed in the Astah ${ }^{\circledR}$ software. The UML document was prepared following four data entry methods, thus enabling four types of features, as shown in Table 1.

Table 1. Work features of the app

\begin{tabular}{|lll|}
\hline Feature & Data type (Ta and RH) & Data source (Ta and RH) \\
\hline Outdoor & Automatic (real time) & Satellite \\
Indoor & Automatic (real time) & Arduino® sensor \\
Manual & Manual & User \\
Forecast & Automatic (real time) & Satellite \\
\hline
\end{tabular}

$\mathrm{Ta}=$ air temperature; $\mathrm{RH}=$ relative humidity

The "Outdoor" feature refers to the diagnosis of the animals' heat stress based on the use of input data (Ta and RH) extracted in real-time. An API (Application Programming Interface) made 
Vol. 06, No. 03; 2021

ISSN: $2456-8643$

available by OpenWeather was used, which offers updated meteorological data captured by Satellite. The license to use the API service is described by Creative Commons AttributionShareAlike 4.0 International (CC BY-AS 4). The "Indoor" feature purpose was to assess the thermal comfort situation of animals housed in closed facilities, which has microclimate particularities compared to open environments. For this reason, input data recorded by a device developed on the Arduino ${ }^{\circledR}$ platform were developed and used. The sensor was made with a NodeMCU ESP8266 microprocessor, equipped with a DHT11 sensor to collect Ta and RH and communicate via Wi-Fi with a built-in antenna. The "Manual" feature, on the other hand, aimed to obtain a diagnosis of the comfort situation via data entered by the users themselves, allowing the incorporation of test values or providing the assessment of indoor settings for users who do not have the integrated Arduino ${ }^{\circledR}$ sensor. Finally, the "Forecast" feature used the weather forecast data from the API provided by OpenWeather, following the same procedures as the "Outdoor" feature.

Two features were added for a better experience of the app. The first one, the "Registration" feature, aimed to save and retrieve all records kept by the user. The second support feature was a contact screen covering communication channels with the app development team.

Still, in the development of the visual app design, good modeling practices proposed by Boock et al. (2005) and Rucker (2003) were considered, addressing a set of images and terminologies that allow intuitive and easy-to-understand navigation of potential users (farmers, researchers, technicians, among others). The selection of colors to characterize the animals' heat stress was conformed to the commonly adopted standard for the thermal comfort indexes and references the traffic lights: green for the comfort state, yellow for the alert state, and red for the emergency state of heat stress.

\subsection{App development}

After the determination of the app features and design, the development of the mobile application, entitled Animalcomfort, was subdivided into the following elements elaboration: the human-machine interface (HMI), being the app itself; a database, to save the values of Ta and RH exported from the Arduino ${ }^{\circledR}$ device to the "Indoor" feature, recording the activities performed by the user in the app; and a web server for proper communication between application and database. The proposed structural design resembles the communication commonly seen on other mobile devices (Abel et al., 2013). This work opted for the scrum methodology as a software development guide, an agile app production model based on activity backlogs later divided into sprints. Sprints are short iterations (or cycles) of development (Mahalakshmi and Sundararajan, 2013).

\subsection{App validation by users}

This paper presents a development model guided by the user's perspective, and this version of the app was validated according to usability tests. 100 individuals characterized as potential users collaborated with this research. They were chosen following the criteria: (a) already have contact with mobile devices in their daily routine, preferably with cellphones equipped with Android operating system, and (b) engage in activities for livestock production, such as farmers, farm 
Vol. 06, No. 03; 2021

ISSN: $2456-8643$

employees, veterinarians, scientists, and students from agricultural science courses (animal science, veterinary, agronomic engineering and others). Personal information of the interviewees was omitted, and only age, gender, and occupation were recorded. The experiment was approved by the Human Research Ethics Committee of ESALQ/USP ( ${ }^{\circ}$ CAAE 21493019.7.0000.5395).

For the app usability test, an adaptation of the methodology for user tests presented by O'Malley et al. (2014) and Shneiderman et al. (2010) was performed, based on the execution of three phases. The first one was related to the evaluation of the technical effectiveness of the app, in which specific tasks were assigned to users to perform using the app. The tasks were: 1) Open the application, select the "pigs" production, select "sows" as growing stage, open the "Outdoor" feature, save the reading, adding an identification number. 2) Return to the main menu, select the "Manual" feature, enter the value of $25^{\circ} \mathrm{C}$ for air temperature and $70 \%$ for relative humidity, obtain the result, save the reading by adding the same identification number. 3) Return to the main menu, select the "Registration" function, type the identification number registered in the previous steps, search for the content, export the content to an Excel spreadsheet.

The technical effectiveness of the app test was completed when the user indicated the conclusion of each task (whether successful or not). The evaluation of the performance of the users followed the scores: 0 (failed to develop the task), 1 (task accomplished, with some degree of difficulty), and 2 (task successfully completed, without difficulties). The second phase involved evaluating the user's relative efficiency using the software. It was measured the time used for each individual to perform each task of the technical effectiveness test.

The third phase was characterized by a user satisfaction questionnaire applied to the interviewee after executing the first two phases. In this test, adaptations were made to the questionnaires proposed by Padilha (2004) and Santos (2015), and the precepts established by ISO/IEC 9126 (1991) and adapted in NBR 13596: 1996 (for app satisfaction).

The questionnaire for assessing user satisfaction was composed of 4 main criteria. Concerning the Layout, users were asked whether Q1) The images are understandable; Q2) The graphic elements are well organized on the screen; Q3) The visual elements help understand how the app works; Q4) The number of colors used is adequate. Regarding the terminologies used in the app, users were asked whether Q5) The chosen font and font size are satisfactory; Q6) The terms used are understandable and unambiguous. Considering the system usability, volunteers were asked whether Q7) It is easy to understand the concept and scope of the app; Q8) The running time of the app is adequate; Q9) The commands are self-explanatory; Q10) The learning time of the app is short. Finally, regarding the general impressions of the app's experience, users were asked whether Q11) The app is clear and objective; Q12) The app is easy to use; Q13) The app is useful; Q14) They would use the app again.Each proposed question was an affirmative that allowed responses of the type "Totally disagree" (score 1); "Disagree" (score 2); "Neutral" (score 3); "Agree" (score 4), and "Totally agree" (score 5).

\section{RESULTS AND DISCUSSION}

\subsection{App design, development and execution}


As the first stage of the app design, Figure 2 presents the use case diagram resulting from the functions expressed in Table 1. Initially, it was up to the user to determine its location (which can be done manually or via the device's GPS) and then, obligatorily, choose the animal of interest and the growing stage. Note that only the use case "contact developers" is independent of the use case "determine species/stage of interest," which keeps executing the programmed features blocked when not selected. The use case "determine species/stage of interest" allows the user to perform the four main tasks (Table 1). The features are associated with the record reading use case, which saves the values recorded in the use cases connected to it.

According to Bezerra (2007), a use-case diagram is an essential tool for structuring the system from the user's point of view, explaining the app goals, the steps required to perform the features, and the communication between the proposed tasks.

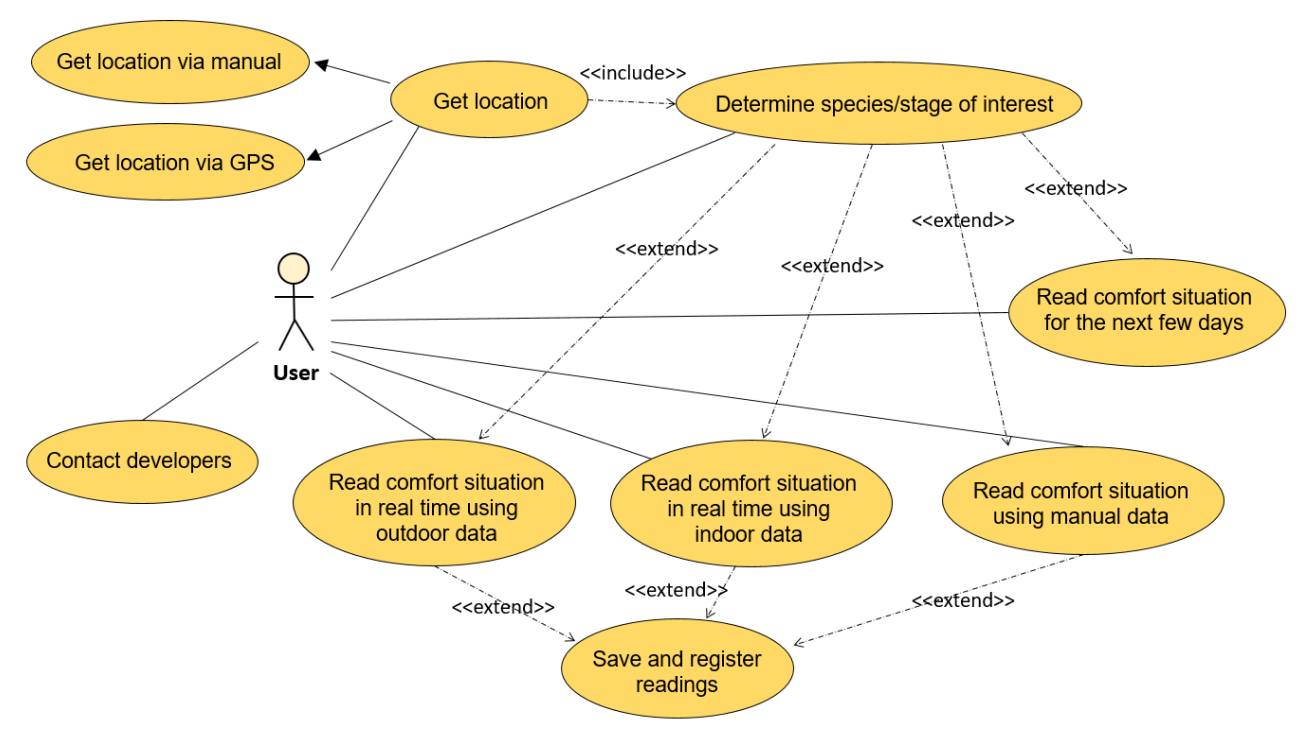

Figure 2. Diagram of use cases for the Animalcomfort project

Based on the use-case diagram, the creation of eight screens were proposed, as follows: 1) the splash screen, containing the logo and the current version of the software, which is a standard development screen for most mobile applications (Ahmed et al., 2019); 2) the main menu, containing the location obtained manually or automatically (by GPS), buttons for choosing the animal and growing stage, the icons of the features and the Ta and RH collected automatically (by Satellite); 3) screen for the "Outdoor" feature; 4) screen for the "Indoor" feature; 5) screen for the "Manual" feature, containing boxes for entering the input data (Ta and $\mathrm{RH}$ ) manually by the user; 6) screen for the "Forecast" feature; 7) screen for the "Registration" function, 8) contact screen. 
Figure 3 shows the main results of the software (English version). The software was also developed in Portuguese, as Brazil is a major producer of animal protein. Its territory is located in hot climates, with heat stress being a relevant issue. The Portuguese version was used in user validation.

On the main screen (Figure 3A), the location - Piracicaba/Brazil in this specific case - is entered automatically. The values of Ta and $\mathrm{RH}$, coming from the Satellite, are displayed in the lower quadrant of the app. Notice that the four reading features of Animalcomfort are disabled, being activated only after choosing the production and the animal of interest. As an example of a reading screen, Figure 3B presents the diagnosis of the comfort situation for broiler birds in the first week of life in an indoor environment. The emergency situation is due to the low ambient temperature, as these animals are thermally comfortable in warmer environments.

A set of recorded data is shown in Figure 3C, in the "Registration" screen. In that screen, it is possible to observe the date and time of the reading, the animal and its evaluated growing stage, the type of reading, and the heat stress situation. Figure 3D shows the data exported to an Excel spreadsheet. In addition to the same records presented in the app, the spreadsheet also displays the $\mathrm{Ta}, \mathrm{RH}, \mathrm{Pa}$, and $\mathrm{h}$ collected during reading.
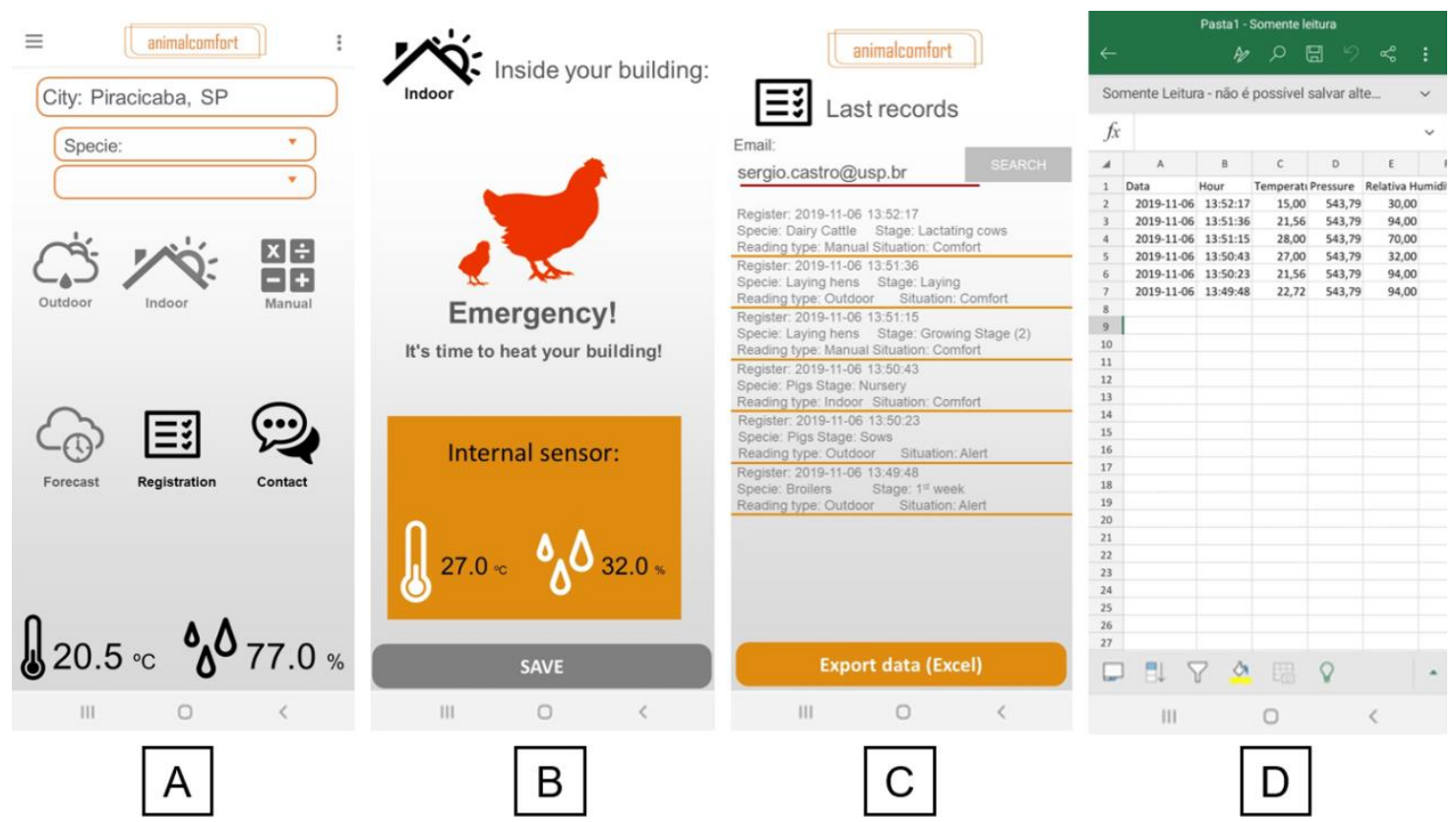

Figure 3. Set of screens: (A) main screen; (B) screen for "Indoor" feature; (C) screen for "Registration" feature and (D) Excel with exported records.

\subsection{User validation}

Usability tests were applied to potential users of the app, which are divided into three major groups: farmers and employees (35\% of them), whose age average was 37 years old, being $66 \%$ 
men and 34\% women; Professors and scientists totalize $27 \%$ of them, whose age average was 33 years old, $41 \%$ women and 59\% men; and students from courses related to agricultural sciences (38\% of the interviewed), whose age average was 24 years old, comprising $29 \%$ men and $71 \%$ women.

Table 2 presents the results - without group distinction group - for evaluating the app's technical effectiveness, given by the frequency of the scores (\%), and the evaluation of the relative efficiency of the user, presented by the tasks execution time (seconds).

Table 2. Technical effectiveness of the app and the relative efficiency of the user.

\begin{tabular}{|llllll|}
\hline & \multicolumn{2}{l}{ Technical effectiveness of the app** } & \multicolumn{2}{l|}{ Relative efficiency of the user } \\
\cline { 2 - 6 } & $\mathbf{0}(\%)$ & $\mathbf{1}(\%)$ & $\mathbf{2}(\%)$ & $\begin{array}{l}\text { Average } \\
\text { (sec) }\end{array}$ & $\begin{array}{l}\text { Standard deviation } \\
\text { (sec) }\end{array}$ \\
\hline $\mathbf{1}$ & 0 & 0 & 100 & 40 & 12 \\
$\mathbf{2}$ & 0 & 26 & 74 & 42 & 15 \\
$\mathbf{3}$ & 0 & 0 & 100 & 25 & 6 \\
\hline
\end{tabular}

*Tasks: 1) Open the application, select "pigs" production, select "sows" as growing stage, open the "Outdoor" feature, save the reading, adding an identification number; 2) Return to the main menu, select "Manual" feature, enter the value of $25^{\circ} \mathrm{C}$ for air temperature and $70 \%$ for relative humidity, obtain the result, save the reading by adding the same identification number; 3) Return to the main menu, select the "Registration" function, type the identification number registered in the previous steps, search for the content, export the content to an Excel spreadsheet.

**Scores: 0) failed to develop the task; 1) managed to accomplish the task, with some degree of difficulty; 2) task successfully completed, without difficulty.

Considering the results from the app's technical effectiveness, it is remarkable that tasks 1 and 3 were carried out without any apparent difficulty: all respondents reached a score of 2 for both tasks. In addition, all users could complete activity 2 , although $26 \%$ of them had difficulties carrying it out (score 1). This issue occurred mainly due to the confusion about the "ok" key on the keyboard used to add the manual data: this button was configured to delete the data and not suspend the keyboard's use. Comparing the groups, $75 \%$ of score 1 cases in task 2 come from groups formed by farmers and researchers.

In the evaluation of the relative effectiveness of the user, task 1 was performed in approximately 40 seconds (minimum of 22 and maximum of 75 seconds), while task 2 was completed in approximately 42 seconds (minimum of 16 and maximum of 80 seconds). Task 3 was performed in around 25 seconds (minimum of 17 and maximum of 36 seconds). When compared to a specialist, an expert user of the app could perform tasks 1,2, and 3 within 13, 14, and 8 seconds, respectively. 
Vol. 06, No. 03; 2021

ISSN: $2456-8643$

Sectioning in groups, students did all the tasks in a shorter time when compared to researchers and farmers. The students obtained an average of 35 seconds for task 1, 38 seconds for task 2, and 34 seconds for task 3 . The group of farmers and employees demanded 41 seconds for task 1 , 48 seconds for task 2 , and 26 seconds for task 3 . The group of faculty members and scientists performed within a period close to the farmers and employees: 45 seconds for task 1, 40 seconds for task 2 , and 27 seconds for task 3 .

The results of the questionnaire to assess the usability of the app are subdivided into four evaluated criteria. When asked about the layout/design of the app, $81 \%$ of the individuals being assessed totally agreed (score 5) that the images are understandable (Q1), while $19 \%$ evaluated the question with a score of 4 . Similar results were obtained for the organization of the screen elements (Q2), with $24 \%$ of the subjects indicating score 4 and $76 \%$ indicating score $5.6 \%$ of individuals scored 3 when asked if the graphic elements helped understand how the app works (Q3), while $23 \%$ of individuals evaluated the number of colors used with the same score (Q4). Although score 5 was more frequent in all questions related to design, the results indicate that new efforts should be applied in the definition of color palettes and more understandable and intuitive graphic elements.

Considering the second criterion, about terminology, $11 \%$ of the individuals scored 3 when asked about the font and font size (Q5), while $29 \%$ scored 4 and $60 \%$ scored 5 . Asked if the words used are understandable and unambiguous (Q6), most interviewees gave the maximum score $(82 \%)$, and the remaining scored 4 . The results suggest a good reception of the words, fonts, and font size used in the app, requiring enhancements in the last two items.

The third criterion aimed to assess the degree of difficulty in handling and interpreting the operation of the Animalcomfort app. It is worth noticing that the interviewees made the first contact with the app during the evaluation. $77 \%$ of the individuals agreed, with a score of 5 , that the concept and application of the app are easy to understand (Q7). The rest replied with a score of 4. The app execution time (Q8) accumulated $94 \%$ of the frequency with a score of 5. The next question was the only one from the learning criterion that presented a score of $3(13 \%)$ answered when the interviewees were asked if the commands are self-explanatory (Q9). Finally, similar results to Q7 were obtained when dealing with the time necessary to learn how to use the app, once $82 \%$ of the interviewees totally agreed that the software did not require much time to understand its functioning $(\mathrm{Q} 10)$.

The last criterion resulted in general impressions about the proposal and usability of the Animalcomfort app, in which all questions were scored with 4 and 5. As a result, $93 \%$ of respondents fully agree that the app is clear and objective (Q11), 88\% gave the same score when asked if the app is easy to use (Q12), 95\% totally agreed that the app is useful (Q13) and 89\% totally agrees that they would use the app again (Q14). It is also important to highlight that all 14 questions obtained a higher frequency of answers pointing to the maximum score.

When the proposals presented in the project (initial version) were compared to theversion presented for testing (beta version), it is noted that it is necessary to make few adaptations to meet the user's demands. Among such improvements that were evidenced by the results of the 
Vol. 06, No. 03; 2021

ISSN: $2456-8643$

tests, the following ones stand out: automate and adjust the digitization keyboard; pay more attention to choosing the color pattern design; add clear, self-explanatory icons; add a direct icon to return to the main screen on the screens of each function; and correct errors in reading the letters accompanied by special characters.

Rocha and Baranauskas (2003) highlight that the evaluation of a technology made by the final user of the system is of great value to understand, in fact, the critical points of the elaborated software, allowing the developers to recognize issues and consider new strategies. However, it is essential to emphasize that none of the works that present the development of apps for the diagnosis of thermal comfort showed in their results the validation of the software from the user's perspective.

\section{CONCLUSION}

Animalcomfort is an app that uses psychrometric principles - based on the specific enthalpy of the air - to indicate the thermal comfort situation of livestock animals, using different input data sources according to the user's needs and availability. In this way, the mobile app makes it accessible to several users - of different backgrounds and ages - who work directly with the livestock production segment, appropriating processing that requires specialized knowledge and time when done conventionally. The UML project, combined with Scrum development practices, made it possible to develop the software in a less bureaucratic way without losing the consistency of the initial documentation. The usability results indicated that users encountered few challenges in performing practical tasks when using the app. In addition, the interviewees evaluated positively, with scores equal to or above 3 , all the usability criteria of the app, showing great potential for commercial usage.

Funding: This work was supported by the Coordination for the Improvement of Higher Education Personnel - Capes.

\section{REFERENCES}

Abel, O., Shatunov, A, Jones, A.R., Andersen, P.M., Powell, J.F., Al-Chalabi, A., 2013. Development of a smartphone app for a genetics website: the amyotrophic lateral sclerosis online genetics database (ALSoD). JMIR mHealth and uHealth, 1(2), e18. https://doi.org/10.2196/mhealth.2706

Ahmed, S.A., Parvez, T., Dey, P.R., 2019. Mobile App-Dhaka City Guide. Daffodil International University, 39.

Associação Brasileira de Normas Técnicas, 1996. NBR 13596: tecnologia de informação avaliação de produto de software - características de qualidade e diretrizes para o seu uso. Rio de Janeiro, 10p.

Aziz, Z., Varma, G.G., Raji, K., Gleeja, V.L, 2016. Influence of temperature humidity index on the physiological parameters and growth rate of crossbred cattle calves. International Journal of Applied and Pure Science and Agriculture, 2, 187-190. 
Vol. 06, No. 03; 2021

ISSN: $2456-8643$

Bezerra, E., 2007. Princípios de Análise e Projeto de Sistemas com UML. Rio de Janeiro: Elsevier, 2007, $2^{\mathrm{a}}$ edição, 392.

Boock, G., Rumbaugh, J., Jacobson, I., 2005. The Unified Modeling Language User Guide. Pearson Education, $2^{\mathrm{a}}$ ed, 496.

Britto, J.F.B., 2010. Considerações sobre psicrometria. Revista SBCCv. 45, 35-41.

Brown-Brandl, T.M., Nienaber, J.A., Eigenberg, R.A., Hahn, G.L., Freetly, H., 2003. Thermoregulatory responses of feeder cattle. Journal of Thermal Biology, 28(2), 149-157. https://doi.org/10.1016/S0306-4565(02)00052-9

Chu, C.M., Jong T.L., 2008. Enthalpy estimation for thermal comfort and energy saving in air conditioning system. Energy Conversion and Management, 49, 1620-1628. https://doi.org/10.1016/j.enconman.2007.12.012

Cowley, F.C., Barber, D.G., Houlihan, A.V., Poppi, D.P., 2015. Immediate and residual effects of heat stress and restricted intake on milk protein and casein composition and energy metabolism. Journal of Dairy Science, 98(4), 2356-2368. https://doi.org/10.3168/jds.2014-8442

Dalmedico, G., Abreu, P.G., Coldebella, A., Santos Filho, J.I., 2016. Conforcalc-manual do usuário. Embrapa Suínos e Aves-Fôlder/Folheto/Cartilha (INFOTECA-E).

Gao, S.T., Guo, J., Quan, S.Y., Nan, X.M., Fernandez, M.S., Baumgard, L.H., Bu, D.P., 2017. The effects of heat stress on protein metabolism in lactating Holstein cows. Journal of dairy science, 100(6), 5040-5049. https://doi.org/10.3168/jds.2016-11913

Heidari, H., Golbabaei, F., Shamsipour, A., Rahimi Forushani, A., Gaeini, A., 2016. Determination of air enthalpy based on meteorological data as an indicator for heat stress assessment in occupational outdoor environments, a field study in Iran. Journal of Research in Health Sciences, 16, 133-140.

Heidari, H., Rahimifard, H., Mohammadbeigi, A., Golbabaei, F., Sahranavard, R., Shokri, Z., 2018. Validation of air enthalpy in evaluation of heat stress using wet bulb globe temperature (WBGT) and body core temperature: A case study in a hot and dry climate. Health and Safety at Work, 8, 81-92.

Kang, H., Park, H.A., 2016. A mobile app for hypertension management based on clinical practice guidelines: development and deployment. JMIR mHealth and uHealth, 4(1), e12. https://doi.org/10.2196/mhealth.4966

Kresta, S., Ayranci, I., 2018. Psychrometric charts in color: An example of active learning for chemical engineering students and faculty members. Education for Chemical Engineers, 22, 1419. https://doi.org/10.1016/j.ece.2017.07.003

Krishnan, G., Bagath, M., Pragna, P., Vidya, M.K., Aleena, J., Archana, P.R., ... Bhatta, R., 2017. Mitigation of the heat stress impact in livestock reproduction. Theriogenology, 4, 63-86. http://dx.doi.org/10.5772/intechopen.69091 
Vol. 06, No. 03; 2021

ISSN: $2456-8643$

Liu, C.Z., Au, Y.A., Choi, H.S., 2014. Effects of freemium strategy in the mobile app market: An empirical study of google play. Journal of Management Information Systems, 31(3), 326354.

Mahalakshmi, M., Sundararajan, M., 2013. Traditional SDLC Vs Scrum Methodology-A Comparative Study. International Journal of Emerging Technology and Advanced Engineering, 3(6), 192-196.

Martello, L.S., Savastano Junior, H., Silva, S.L., Titto, E.A.L., 2004. Respostas fisiológicas e produtivas de vacas holandesas em lactação submetidas a diferentes ambientes. Revista Brasileira de Zootecnia, 33, 181-191.

Nordlund, K.V., Strassburg, P., Bennett, T.B., Oetzel, G.R., Cook, N.B., 2019. Thermodynamics of standing and lying behavior in lactating dairy cows in freestall and parlor holding pens during conditions of heat stress. Journal of dairy science, 102(7), 6495-6507. https://doi.org/10.3168/jds.2018-15891

Nyoni, N.M.B., Grab, S., Archer, E.R., 2019. Heat stress and chickens: climate risk effects on rural poultry farming in low-income countries. Climate and Development, 11(1), 83-90. https://doi.org/10.1080/17565529.2018.1442792

Oliveira Júnior, A.J., Souza, S.R.L., Cruz, V.F., Vicentin, T.A., Glavina, A.S.G., 2018. Development of an android APP to calculate thermal comfort indexes on animals and people. Computers and Electronics in Agriculture, v. 151, p. 175-184. https://doi.org/10.1016/j.compag.2018.05.014

O'Malley, G., Dowdall, G., Burls, A., Perry, I. J., Curran, N., 2014. Exploring the usability of a mobile app for adolescent obesity management. JMIR mHealth and uHealth, 2(2), e29. https://doi.org/10.2196/mhealth.3262.

Padilha, A.V., 2004. Usabilidade na Web: uma proposta de questionário para avaliação do grau de satisfação de usuários do comércio eletrônico. Dissertation. Universidade Federal de Santa Catarina, 104.

Quintão, L.C., Cunha, A.F.D., Bragança, L.J., Coelho, K.S., Nunes, M.F., Saraiva, L.H.G., 2017. Evolution and factors influencing somatic cell count in raw milk from farms in Viçosa, state of Minas Gerais. Acta Scientiarum. Animal Sciences, 39(4), 393-399. http://dx.doi.org/10.4025/actascianimsci.v39i4.35364

Rashamol, V.P., Sejian, V., Bagath, M., Krishnan, G., Archana, P.R., Bhatta, R., 2018. Physiological adaptability of livestock to heat stress: an updated review. Journal of Animal Behaviour and Biometeorology, 6(3), 62-71.

Ribeiro, B.P.V.B., Lanferdini, E., Palencia, J.Y.P., Lemes, M.A.G., Abreu, M.L.T., Cantarelli, V.S., Ferreira R.A., 2018. Heat negatively affects lactating swine: a meta-analysis. Journal of Thermal Biology, 74:325-330. 
Vol. 06, No. 03; 2021

ISSN: $2456-8643$

Rocha, H.V., Baranauskas, M.C.C., 2003. Design e avaliação de interfaces HumanoComputador. Campinas, SP: NIED - UNICAMP, 257.

Rodrigues, V.C., Silva, I.J.O., Vieira, F.M.C., Nascimento, S.T., 2011. A correct enthalpy relationship as thermal comfort index for livestock. International Journal of Biometeorology, 55, 455-459. https://doi.org/10.1007/s00484-010-0344-y

Rucker, R., 2003. Software engineering and computer games. Harlow: Addison-Wesley, 1 ed, 648.

Ryu, M., Yun, J., Miao, T., Ahn, I.Y., Choi, S.C., Kim, J., 2015. Design and implementation of a connected farm for smart farming system. In: 2015 IEEE Sensors, 1-4. https://doi.org/10.1109/ICSENS.2015.7370624

Santos, L., 2015. Teste e avaliação de usabilidade de app para gestão de diabetes em Android. Dissertation. Faculdade de Ciências, Universidade do Porto, Porto, 87.

Sarnighausen, V.C.R., 2019. Estimation of thermal comfort indexes for production animals using multiple linear regression models. Journal of Animal Behaviour and Biometeorology, 7, 73-77. http://dx.doi.org/10.31893/2318-1265jabb.v7n2p73-77

Shneiderman, B., Plaisant, C., Cohen, M., Jacobs, S.L., 2010. Designing the user interface: strategies for effective human-computer interaction. Boston: Addison-Wesley, 2010.

Slimen, I.B., Najar, T., Ghram, A., Abdrrabba, M., 2016. Heat stress effects on livestock: molecular, cellular and metabolic aspects, a review. Journal of Animal Physiology and Animal Nutrition, 100(3), 401-412. https://doi.org/10.1111/jpn.12379

Wolfert, S., Ge, L., Verdouw, C., Bogaardt, M.J., 2017. Big data in smart farming-a review. Agricultural Systems, 153, 69-80. https://doi.org/10.1016/j.agsy.2017.01.023 